\title{
Older Thai Peoples' Perceptions and Experiences of Major Depression
}

\author{
Duangkaew Kleebthong ${ }^{1,2}$, Sukjai Chareonsuk ${ }^{2} \&$ Lisbeth Kristiansen $^{1}$ \\ ${ }^{1}$ Deparment of Nursing Sciences, Faculty of Human Sciences, Mid Sweden University, Sundsvall, Sweden \\ ${ }^{2}$ Boromarajonani College of Nursing, Chakriraj, Thailand \\ Correspondence: Duangkaew Kleebthong, PhD student, Department of Nursing Sciences, Faculty of Human \\ Sciences, Mid Sweden University, Holmgatan 10, SE-85170 Sundsvall, Sweden. Tel: 46-70-252-8789.
}

Received: April 26, 2017 Accepted: June 5, 2017 Online Published: June 16, 2017

doi:10.5539/gjhs.v9n9p26 URL: https://doi.org/10.5539/gjhs.v9n9p26

\begin{abstract}
Background: Depressive disorders are common mental health problems and may be disabling among the general older population. Although older people have significant symptoms of depression, the symptoms are likely to be underreported. The condition often co-exist along with somatic ill and has often been unrecognized. The aim of the study was to explore and understand the perceptions and experiences of older Thai people diagnosed with major depressive disorder.
\end{abstract}

Methods: A qualitative inductive research design was used and latent content analysis was utilized. The data were collected through face-to-face, in-depth interviews. Fourteen older people diagnosed with major depressive disorder were selected for participant using purposive sampling.

Findings: Older Thai peoples' perceptions and experiences of depression were abstracted into two themes. First theme was leading a life in detachment, which included three subthemes: living with meaninglessness, holding distress with one's self, and feeling judged by surrounded people. The second theme was inconvenience of approaching mental health treatment, which included two subthemes: sensing an unapproachable health care service, and lacking knowledge about clinical depression.

Conclusion: Older Thai peoples' perceptions and experiences of major depression were affected with high level suspected existential loneliness that might even be worse in a collect oriented society as in the Thai context. Further, it seem hard to approach the mental health care. The central reason for this is interpreted as lack of mental health literacy, and in this case, specifically, knowledge on depression. Future studies should focus on relatives' experiences of living with an older family member that suffered from major depression, and on the state of mental health literacy in the rural Thai population.

Keywords: major depression, qualitative latent content analysis, rural, Thai

\section{Introduction}

Depression is the most common mental health problem worldwide (Barcelos-Ferreira, Izbicki, Steffens, \& Bottino, 2010; Byers, Yaffe, Covinsky, Friedman, \& Bruce, 2010; Fiest, Currie, Williams, \& Wang, 2010; Monteso et al., 2012; Tiwari, Pandy, \& Singh, 2012; Verhaak, Dekker, de Waal, van Marwijk, \& Comijs, 2014), and is one of the leading causes of disabilities (Lopez, Mathers, Ezzati, Jamison, \& Murray, 2006; Ferrari et al., 2013). It should be kept in mind that depression is the most important predictor of suicide ideation and suicide attempt (Indu et al., 2017). Globally an estimate of 350 million people experience depression, although many do not acknowledge that they are ill and do not seek treatment (World Health Organization, 2012). In Thailand, the prevalence of depression among a population aged over 45 years was $29.2 \%$ (Wangtongkum, Sucharitakul, Wongjareon, \& Maneechompoo, 2008), but for the segment above 60 years of age it was only $12.78 \%$ (Thongtang et al., 2002). In general, females have higher rates of depression than males, especially older people with disabilities (Pagan-Rodriguez \& Perez, 2012). Compared to older people without depression, older people with the diagnosis showed both central and peripheral signs of inflammation, and enhanced level of a specific translocator protein, which is associated with cardiovascular diseases (Su et al., 2016). Moreover, these patients showed significant gray matter reduction in the whole brain, which is associated with disruption of the neural network that regulates mood and behavior (Stratmann et al., 2014). This might be one reason why people with depression often display a complexity of health issues. Not seldom, this patient group demonstrates several somatic symptoms, which include gastrointestinal, skeletal muscle, and cardiovascular complaints, in contrast to describing non-physical criteria for depression 
(Arroll et al., 2009; Hegeman, Kok, van der Mast, \& Giltay, 2012). Older people with depression is often underdiagnosed, undertreated, or mistreated because depression may co-exists as a comorbidity in combination with somatic illness, and further, the older patients may believe that a depression is a part of normal life (Maiera, 2010; Gellis, 2010). However depression is not part of normal aging, in contrary older people as a population group displays the lowest prevalence (Smyer \& Qualls, 1999). Besides, health care providers less often recognize that older patients suffer from depression (Piek et al., 2012). Old age depression may occur after stressful life events such as death of a beloved person, loneliness, serious health problems, and the lack of economic resources (Maiera, 2010; Monteso et al., 2012; Baiyewu, Yusuf, \& Ogundele, 2015). An Asian comparative study identified stressful life event for a Thai population prior to the onset of depression, and found that any stressful life events, financial crisis, and serious illness were the three main events (Park et al., 2015). A systematic review revealed that older people with depression lowered the health related quality of life (Renaud \& Bedard, 2013). The possibility of recurrence could occur even after more than a decade (Crona \& Bradvik, 2012). At five years of follow-up, a study reported that the recurrence rate was $31.5 \%$ (Bukh, Andersen, \& Kessing, 2016).

The majority of literature investigating depression in older people appears to be conducted quantitatively. Another field of the research have focused on the perspective of the patients with depression. For instance, a literature synthesis of older persons' narratives showed that, when suffering from depression they engaged three central strategies to survive; the need for courage, strength and self-reliance; the meaning of responsibility; and wearing a mask of normalcy to hide shame (Holm \& Severinsson, 2014). While, the perspective from patients' family showed that to them the relative's major depression was trying and that it brought them into severe stressful life situations (Ahlstrom, Skarsater, \& Danielson, 2009).

Due to the complexity of older peoples' health status with co-morbidities, the depression symptomatology it has often been undetected (Licht-Strunk, Beekman, Haan, \& Marwijk, 2009). Besides, there may be some misunderstanding that depression is a part of normal aging process (Smyer \& Qualls, 1999). Further, healthcare providers do not pay attention and are not sufficiently aware as they also display the position that depression is a part of the normal aging process (Bryant, 2010). It that respect, the healthcare providers lack knowledge and competence. Moreover, there is a need to more deeply comprehend how these older people understand and recognize depressive symptoms in their daily lives. The literature search identified no study on older people with depression and their experiences of living with the condition in a Thai rural context. To fill this gap in knowledge, the current study aimed to explore and understand the experiences and perceptions of older Thai people suffering from a diagnosed major depression.

\section{Method}

\subsection{Design}

This study had a qualitative research design and used an inductive approach inspired by Graneheim and Lundman (2004) and Patton (2015) and their interpretation of latent content analysis. The qualitative work is based on the ontological assumption that peoples' conceptualization is multiple and that subjective reality exists. This study focused on individuals' interpretation of a variation of experiences, aiming to gain better understanding of the experiences of older Thai people whom displayed depression.

\subsection{Setting}

The study took place in rural areas of Kanchanaburi, the western province in Thailand. Its territory covered an area of approximately 19,473 square kilometers. The province contained 13 districts, and had a population of approximately 885,000 people, the older people accounted to $12.86 \%$ (Bureau of registration of administration, 2016). Most of the inhabitants are employed in agriculture. Generally older people in the rural area of Thailand are considered poor. Each province had a provincial hospital and one hospital for every district and one health center for every sub-district (Tambon in Thai). Fifteen hospitals were located in Kanchanaburi. The setting was the primary care of public health in Thailand.

\subsection{Participant and Sample Recruitment}

The participants were recruited and selected using purposive sampling. The psychiatric nurses were asked to mediate the contact with patients who fullfilled the inclusion criteria that were 60 years of age and over, diagnosed with major depressive disorder according to the criteria of the Diagnostic and Statistical Manual of Mental Disorders (DSM V; F. 32) (American Psychiatric Association, 2013), being treated by antidepressant, and being able to speak and understand Thai and agree to take part in this study. Then the first author contacted the patients and gave verbal information about the details of the study, and that the interviews would be treated confidentially and for research purpose only. Afterward, the participants gave their informed consent. Twenty-two older Thai 
people whom displayed depression were invited for participation but due to time limitation, a total of fourteen patients agreed to participate. All were women, age between 60 to 79 years (median 67 years), and half of them lost husband and currently living with their children.

\subsection{Ethical Consideration}

The study was conducted after approval from the Research Ethics Committee at Makaruk hospital (MKH, 118-2015). Participants were informed that their participation was voluntary and that they could withdraw at any point during the interview without any consequence on the healthcare provision. All data was handled according to the principle of confidentiality. If the interview awake any inconveniency, a pre-arrangement was made that the participants would be referred to the general practitioner. This was never needed as the interviewees expressed their gratitude to being listened and taken interest in.

\subsection{Data Collection}

The data was collected through face-to-face, individual in-depth interviews (Polit \& beck, 2016). The first author contacted each participant to make an appointment that was convenient for the participant and asked for permission to use digital recording during the interview. Ten interviews were conducted in private room at the outpatient clinic and four interviews at the patients' homes. First, the first author asked general questions and then used open-ended questions to encourage the participant to openly tell their stories. The interview questions were concentrated in the following domain; please tell me about your experience of depression? To probe further, the participants were asked these questions; could you please describe your experiences in more detail? Could you please give me some examples? The digital recorded interviews were transcribed into word document files. Each interview session took approximately 40-90 (median 55) minutes from June to November 2016. In all approximately 150 pages was generated.

\subsection{Data Analysis}

To analyze the data, qualitative latent content analysis described by Graneheim and Lundman (2004) and Patton (2015) was used. The first step, the text was read several times to achieve an overall understanding and marking each sentence revealed the experience of depression. The second step, then, the text that could be the words, phrases, sentences, and paragraphs was divided into meaning units that relate to the study aim. In the third step, the meaning units were condensed while still keeping the original essence of the text, which were then labeled with codes according to their content. The fourth step, the various codes with the similar content were then group together and identified into subthemes related to the objectives of the study. Finally, the subthemes were abstracted, sorted and formulated into themes. An example of the process of the analysis that is the way in which the themes were developed from meaning units, condensed meaning unit, coding, and subthemes are shown in Table 1. Please see below.

Tables 1. Example of analysis process

\begin{tabular}{|c|c|c|c|c|}
\hline Meaning Units & Condensed meaning unit & Coding & Sub themes & Themes \\
\hline $\begin{array}{l}\text { I am always thinking that I don't want } \\
\text { to live. I then get a rope to hang my } \\
\text { neck and think that no matter what } \\
\text { other says, I will not live anymore. The } \\
\text { idea just comes automatically. }\end{array}$ & $\begin{array}{l}\text { She is always } \\
\text { automatically thinking } \\
\text { that she does not want to } \\
\text { live. Then, she gets the } \\
\text { rope to hang her neck. }\end{array}$ & $\begin{array}{l}\text { Planning to } \\
\text { die }\end{array}$ & $\begin{array}{l}\text { Living with } \\
\text { meaninglessness }\end{array}$ & $\begin{array}{l}\text { Leading a life in } \\
\text { detachment }\end{array}$ \\
\hline $\begin{array}{l}\text { The doctor appointed me every } 2 \\
\text { month. It was not so often but I } \\
\text { sometimes, couldn't come as appointed } \\
\text { because of inconvenience in travelling. } \\
\text { I have to walk to hospital, which take a } \\
\text { long time. I have to leave home very } \\
\text { early otherwise it will too hot to walk in } \\
\text { the sunlight and I would faint. }\end{array}$ & $\begin{array}{l}\text { The doctor appointed the } \\
\text { patient every second } \\
\text { months, but the patient } \\
\text { was not able to meet the } \\
\text { doctor because of } \\
\text { inconvenience in } \\
\text { travelling. }\end{array}$ & $\begin{array}{l}\text { Lacking } \\
\text { access to } \\
\text { health care } \\
\text { services }\end{array}$ & $\begin{array}{l}\text { Sensing an } \\
\text { unapproachable } \\
\text { health care services }\end{array}$ & $\begin{array}{l}\text { Inconvenience of } \\
\text { approaching } \\
\text { mental health } \\
\text { treatment. }\end{array}$ \\
\hline
\end{tabular}

\subsection{Trustworthiness}

To achieve credibility, the interviews were addressed by the heterogeneous participants. The participants were 
recruited with various stage of their depression such as current episode, recover, and long term illness. The Thai version Patient Health Questionnaire (PHQ-9) was used to assess based on DSM-V criteria for major depressive episode. The authors attempted to increase the richness of data by starting from having a good relationship with the interviewees. They also allocated sufficient time for investigation and following step-by-step of data analysis process. The authors read and discussed the meaning units, including condensed meaning units, coding, subthemes, and themes and critical analysis during the whole process. Two participants were asked to review the findings (subtheme) and agree with the result that linked to their experiences (member checking). The research team had completely agreed with the findings after discussion.

\section{Findings}

Older Thai peoples' perceptions and experiences of depression were based on current situation as well as the context of their lives where are rural area in Thailand. In this study, the finding are abstracted their experiences into two themes: Leading a life in detachment and inconvenience of approaching mental health treatment. These themes are discussed in more detail in the following sections. Please see table 2 below.

Table 2. Overview of themes and subthemes

\begin{tabular}{ll}
\hline Themes & Subthemes \\
\hline Leading a life in detachment & Living with meaninglessness \\
& Holding distress with one's self \\
& Feeling judged by surrounded people \\
Inconvenience of approaching mental health treatment & Sensing an unapproachable health care service \\
& Lacking knowledge about clinical depression \\
\hline
\end{tabular}

\subsection{Leading a Life in Detachment}

This theme was based on the abstraction of the content in the following three subthemes: living with meaninglessness, holding distress with one's self, and feeling judged by surrounded people.

\subsubsection{Living with Meaninglessness}

The participants expressed that suffering from depression meant that they were living with meaninglessness. The meaninglessness became a central part of their lives. Several participants experienced that they lacked energy and were automatically thinking that they did not want to live. Please see table 1 above.

Another aspect of the experience of living with meaninglessness was a very inactively mode of living as the participants just wanted to lie down or quietly sit on the bed almost the whole day. Further, and there were no energy to paid attention to things that they needed to do such as cooking and washing. One participant said:

"I am doing activities with an absent-mind. It started with insomnia for a half month ago and afterwards, I became unhealthy skinny. I didn't want to meet people and didn't want to eat or do anything. When cooking, I did it with carelessness and didn't concern for its taste". (Participant 10)

Some participants displayed a meaningless life as they felt drawn to the past and always thought of the death of their spouse and love ones. They seldom looked at the future as stated by one participant.

"I always thought that before we lived together: me, my husband and our child. One day my husband and my child are died, how can I live? I thought and sometimes spoke out that I want my dead husband and child come back, please let me see the both of you. When time passed for a long while, I could stop thinking but for a few days later these thoughts was coming back. This cycle happened for several years". (Participant 11)

\subsubsection{Holding Distress with One's Self}

The signs and symptoms of depression occurred over time, but the participants did not understand that they were related to depression. There were times, where they did not want to talk to anyone, and where they kept the mental health concerns to themselves. Sometimes they wanted to talk to their children, but they did not want to disturb. They still held a burden of guilt and shame over not being an appropriate parent. This is an example of one informant statement.

"I was offended and felt uncomfortable or worried by my daughter's words. She said that she did not want a mother. This sentence kept repeating itself in my head. I did not know how to forget it and did not know how to talk about 
it. It was not good to speak out. I did not know whom I could talk to. I then had to keep it to myself. I did not dare telling anyone". (Participant 9)

Frequently, the participants could not express their stress. The participants depended on financial resources and residence from their children. Further, they were worried that they should become a burden to their children, and how they should managed to live their lives being dependent.

"If I said something bad about the family, I would be in trouble if the children had heard it. I am alive because they provide me with a home and food. If they stopped giving it to me, I would starve to death. Sometimes, I told them I want to visit my cousins, but my children would suspect that I would bring unhappiness to the family by talking out side the closest family". (Participant 3 )

Some participants described holding distress with one's self generating a feeling of loneliness. They found no joy to be with their relatives, although they were usually invited to jointly going to the temple. They withdrew from everyone and situation that they were in the past. One participant described this experience as followed:

"I was talking less because I was sick with a disease unlike anyone else. I did not want to talk at all and answer any invitation. I stayed only at home not going anywhere, which was different from the past, where I went to making merit on every Buddhist Holy Day". (Participant 13)

\subsubsection{Feeling Judged by Surrounded People}

Most of participants expressed that suffering from depression meant that they were feeling judged by surrounded people. Apparently, they withdrew from others and kept their distress to themselves. They have had trouble living with their neighbors. The participants expressed that they could not understand what was happening to them, and therefore they were unable to explain it to the neighbors. Frequently, the participants were judged that they were crazy by their neighbors. As stated by one participant:

"I just felt depressed without a reason that I barely couldn't hold on. When I talked to a neighbor who turned on radio, I switched off his radio asking him to shut it down because I felt uncomfortable to listen. I got home or when motorcycles rode pass my house, I used to quarrel with them or people surrounded my path. Other people said that I have gone crazy, and I thought that I brought the stigma to my family". (Participant 7)

Another aspect of the experience of living with feeling judged by surrounded people was participants always were seen that they faked their illness; because they looked like the appearance of normal people.

"For four or five years ago, if I was at home and there are children loudly playing around my house, I will come out and chase them away. Normally, I am kind but when I have symptoms, I will be frustrated, have a headache and can't sleep in the night without taking sleeping pills. People who usually see my symptoms said that I pretend to be sick. They asked why good-looking person like me have to pretend to be mentally ill. I became more stressful and tortured but I didn't know how to do". (Participant 14)

\subsection{Inconvenience of Approaching Mental Health Treatment}

This theme was based on the abstraction of the content in the following two subthemes: Sensing an unapproachable health care services, and Lacking knowledge about clinical depression.

\subsubsection{Sensing an Unapproachable Health Care Service}

Most of participants revealed that they sensed the health care services were hardly accessed or difficult to approach. Although each rural area had a hospital to provide treatment, the participants expressed that they could not go to the hospital because they lived alone and that travelling was difficult. Moreover, they were in a vulnerable position and relied on their children to pick them up to wherever. This is exemplified by the following:

"After I take all medicine as prescribed, I was better and could sleep but I don't go to take more medicine because I couldn't go by myself. I have to go with my child who said going to hospital was bothering him because it took him so much time and he couldn't take a day off so often". (Participant 6)

Some of participants were also described they tried to go to the health care services by themselves but it is so difficult to travel.

\subsubsection{Lacking Knowledge about Clinical Depression}

The majority of participants were unaware that they were experiencing depressive symptoms due to lack of knowledge about signs of clinical depression. Participants sensed something unusual such as being fed up with talking to others and felt depressed a long period. They asked themselves "what has happened to me?" and thought that it would come and go by itself. This is exemplified by the following citation. 
"I saw my friends died one by one. It made me feel depressed, disheartened and thought-overwhelmed. After that I couldn't sleep and couldn't eat. I became skinny. I don't want anything. I felt like this for about a year or two years but I didn't come to see doctor because I thought that it would come and go by itself. However, it did not disappeared, moreover, it got worse. I was skinnier and with a pale face. When I followed up my blood pressure at hypertension clinic, the doctor checked, asked some questions and said that I also had a depression". (Participant 1)

Most of the participants used the law of karma, which according to belief in reincarnation basically meant that any bad deeds in the present life will be punished in the future life, to interpret their illness as the result of an accumulation of merit and demerit. Older people in Thailand are very subservient, which means that they often accept whatever is given to them without complaining. If they are poor or ill in this life, it is because of a consequence of a bad deed in a previous life. This lead to that the participants did not visit mental health care providers, but they usually prayed for better health instead. As reported by one participant:

"I was so stressed and disappoint in my life. I've worked but never earn enough money for a living. My husband didn't help in anything. He was alcoholic. My hope to depend on my son became hopeless; because he was also drug addicted and usually had quarrels with me without a reason. I were aggrieved and thought that I must have done many bad things in past life so I have to repay for them now". (Participant 4)

When asked how the participants understood that they suffered from depression, all of them described that they knew it from the nurses' screening that was conducted when they went to the hospital for other illness such as hypertension, diabetes mellitus. One participant stated:

“At first, I didn't know what make me sick. I just too tired to work and one day I just fainted. When I went to the hospital, I know that I have diabetes. Later, when I came as appointed, the nurse asked me if I was stressed or worried. And she also asked me many more questions, which I rarely remembered but finally, found out that I also had depression". (Participant 2)

\section{Discussion}

The purpose of this study was to describe older Thai people perceptions and experiences of living with major depression. The findings showed that they were: leading a life in detachment, and that they sensed inconvenience of approaching mental health treatment, where the patients were struggling in several aspects. This study found that the depression seemed to interfere negatively in different aspects in the older patients' lives. It affected their views on themselves, their views on family, neighbors, community, and their views on health care. The findings are not unique for the Thai people at the individual patient level. However, the most persistent notion is that older Thai people with depression seemed existentially alone. The traditional Buddha world view may any even worsen the individual suffering as it states that today's suffering many originate from former life mistakes and as such it should be tolerated and learned from (Nilmanat \& Street, 2014). Many Thai individuals understand illness according to Buddhist construction of Karma and reincarnation, where the person that behaved morally bad in a previous life, by karmic healing activities may end the suffering, and ensure a better life next time, and therefore, there is no need to medically treat the illness in present life. The Thai culture is generally a collective oriented one and combined with the Buddhism, the existential loneliness might be even deeper due to that. The findings showed that older Thai people' experienced the depression as living with meaninglessness and this seemed to be central part of their lives. They identified themselves as having been in a state of hopelessness, lacking motivation to live and planning to die. One participant captured the essence of the older people's experience of depression in her statement, "I am always thinking that I don't want to live. I then get a rope to hang my neck and think that no matter what other say, I will not live anymore. The idea just comes automatically". This is in line with another study that showed that the patients suffering from depression had previously attempted suicide in $21.3 \%$ of the cases, and that the current depression episode was the largest predictor of past suicide attempt (Indu et al., 2017). Moreover, a ten years follow-up study found that depression was associated with an increased risk of $77 \%$ for all-causes mortality (van Dijk et al., 2016). This point to the fact that there is a need for a general increase in the population's mental health literacy. When the people have mental health literacy, they can recognize, manage, and prevent themselves from mental disorder (Jorm, 2012).

Older people in this study expressed that they holding distress with one's self as seem they were loneliness. Older people reported that they were not able to initiate and maintain relations with relatives and friends. Their suffering from depression were kept secret, as the older people wanted to hide this shamefulness and guilt from others. Older people may fear the consequences of disclosing the experience to health care providers, family, and friends. It might inhibit the older people from seeking treatments. This is in line with previous studies that reported that patients with depression did not seek treatment because they lacked knowledge (Epstein et al., 2010), and because 
they hide due to a feeling of shame (Holm \& Severinsson, 2014). This study has shown that the older people feeling judged by surrounded people. Older people spoke about that they were crazy and pretended to be ill, and they believed that they did not belong to the same community as their neighbors. Moreover, they believed that the neighbors thought badly about them. This could sign of that they felt stigmatized. This is in line with another study, which showed that self-stigma was positively correlated with depression (Oakley, Kanter, Taylor, Duguid, 2011). Stigma has been identified as a main factor associated with the lack of health care utilization in the treatment of depression and the stigma of mental illness may impair achievement of personal aspirations (Corrigan \& Wassel, 2008). If older people choose not to seek treatment, they will be having serious health and psychosocial burdens of untreated depression. Our study also found that sensing an unapproachable health care service when older people suffered from depression. They expressed that they lacked access to health care services, and efficacy of treatment due to living in dependency on their children. Some older people revealed that they lived alone, and therefore it was difficult to travel because of lack of public transportation in rural area. They occasionally went to a hospital with neighbors when they had worse diseases. In the same way, another study found that women in rural area were less likely to seek treatment of depression (Cadigan \& Skinner, 2015). Though, in our study the reason were of a more practical character. It is supported by a qualitative synthesis study that found that various help seeking behavior was likely due to a range of factors, and divided into four concepts; depression and help-seeking as a threat to individual's Identity, role of social networks in help-seeking, coping strategies as a main factor for treatment delay, and barriers to depression help-seeking (Doblyte \& Jimenez-Mejias, 2017).

More important, the results of this study demonstrated that older people diagnosed with depression were lacking knowledge about clinical depression. Older people thought that symptoms were an inevitable part of old age and a result of karma affecting the present state, so even when they were depressed, disheartened, and overwhelmed for a year or two but they did not want to seek the health care services. Besides, they thought that it would come and go by itself, which is in consistency with previous studies (Maiera, 2010; Gellis, 2010). The results of knowledge about clinical depression are in accordance with the previous studies that found more than half of Korean American older adults had a serious lack of knowledge about various aspects of depression (Jang, Gum \& Chiriboga, 2011), for instance, older people were not aware of sign and symptoms of depression. Then the older people suffered from severe depression and to the extent that they planned to die as the result showed. This result also showed that the depression was detected by tracking chronic illness. They were less likely to seek treatment for depression itself until the nurses checked and identified their depression. This can be an immediately concern for the healthcare provider for providing needed knowledge of depression.

\section{Limitations of Study}

There were 14 older Thai people, living in rural area, obtained purposively for this research. The findings were not referred to all older people especially in other culture. Moreover, the participants did not include any older person who lived in public nursing home. Variation would have been larger if both sexes had been involved in the study. However, with reference to our clinical as psychiatric nurses, we do not believe that the findings would have been different, and subsequently only having female informants is not seen as a limitation.

\section{Clinical Implication}

These findings points at lacking knowledge in some rural Thai older people that suffered from major depression, and there is no reason to assume that the general population differs in that respect. Therefore, the mental healthcare authorities should provide strategies for individual mental health care literacy. Mental healthcare providers play an important role in providing the knowledge of what are mental disorder, and how to seek mental healthcare.

\section{Conclusion}

This study provides new information on older Thai peoples' perceptions and experiences of major depression. These were affected with high level suspected existential loneliness that might even be worse in a collect oriented society as in the Thai context. Further, it seem hard to approach the mental health care. The central reason for this is interpreted as lack of mental health literacy, and in this case knowledge on depression. Future studies should focus on relatives' experiences of living with an older family member that suffered from major depression, and on the state of mental health literacy in the rural Thai population.

\section{Acknowledgements}

The authors would like to acknowledge all the older people in Kanchanaburi who were involved in the study. This study was in part financially supported by Mid Sweden University, Sweden, and Boromarajonani College of Nursing, Chakriraj, Thailand. The funding sources listed had no involvement and no relationships with commercial in this study. 


\section{Authors' Contribution}

D. K. performed the collection of data, analysis and drafted the manuscript. L. K. contributed to the conception, design and analysis of this study. Further, L. K. and S. C. critically reviewed the manuscript and supervised the whole study process. All authors read and approved the final manuscript.

\section{Competing Interests Statement}

The authors declare that there are no competing or potential conflicts of interest.

\section{References}

Ahlstrom, B. H., Skarsater, I., \& Danielson, E. (2009). Living with major depression: experiences from families' perspectives. Scandinavian Journal of Caring Sciences, 23(2), 309-316. https://doi.org/ 10.1111/j.1471-6712.2008.00624.x

American Psychiatric Association. (2013). Diagnostic and statistical manual of mental disorders (5th ed.). Washington, DC.

Arroll, B., Elley, C. R., Fishman, T., Goodyear-Smith, F. A., Kenealy, T., Blashki, G., . . Macgillivray, S. (2009). Antidepressants versus placebo for depression in primary care. Cochrane Database of Systematic Reviews (3), CD007954. https://doi.org/10.1002/14651858.CD007954

Baiyewu, O., Yusuf, A. J., \& Ogundele, A. (2015). Depression in elderly people living in rural Nigeria and its association with perceived health, poverty, and social network. International Psychogeriatrics, 27(12), 2009-2015. https://doi.org/10.1017/S1041610215001088

Barcelos-Ferreira, R., Izbicki, R., Steffens, D. C., \& Bottino, C. M. (2010). Depressive morbidity and gender in community-dwelling Brazilian elderly: systematic review and meta-analysis. International Psychogeriatrics, 22(5), 712-726. https://doi.org/10.1017/S1041610210000463

Bryant, C. (2010). Anxiety and depression in old age: challenges in recognition and diagnosis. International Psychogeriatrics, 22(4), 511-513. https://doi.org/10.1017/S1041610209991785

Bukh, J. D., Andersen, P. K., \& Kessing, L. V. (2016). Rates and predictors of remission, recurrence and conversion to bipolar disorder after the first lifetime episode of depression--a prospective 5-year follow-up study. Psychological Medicine, 46(6), 1151-1161. https://doi.org/10.1017/S0033291715002676

Bureau of registration of administration. (2016). Official statistics registrations system: Demographic and household statistics. Retriveed from http://stat.dopa.go.th/stat/statnew/upstat_age_disp.php

Byers, A. L., Yaffe, K., Covinsky, K. E., Friedman, M. B., \& Bruce, M. L. (2010). High occurrence of mood and anxiety disorders among older adults: The National Comorbidity Survey Replication. Archives of General Psychiatry, 67(5), 489-496. https://doi.org/10.1001/archgenpsychiatry.2010.35

Cadigan, R. J., \& Skinner, D. (2015). Symptoms of depression and their management among low-income African-American and White mothers in the rural South. Ethnicity \& Health, 20(3), 293-308. https://doi.org/ $10.1080 / 13557858.2014 .921889$

Chan, S. W., Chien, W. T., Thompson, D. R., Chiu, H. F., \& Lam, L. (2006). Quality of life measures for depressed and non-depressed Chinese older people. International Journal of Geriatric Psychiatry, 21(11), 1086-1092. https://doi.org/ 10.1002/gps.1611

Corrigan, P. W., \& Wassel, A. (2008). Understanding and influencing the stigma of mental illness. Journal of Psychosocial Nursing, 46(1), 42-48.

Crona, L., \& Bradvik, L. (2012). Long-term course of severe depression: late remission and recurrence may be found in a follow-up after 38-53 years. Mental Illness, 4(2), e17. https://doi.org/10.4081/mi.2012.e17

Doblyte, S., \& Jimenez-Mejias, E. (2017). Understanding Help-Seeking Behavior in Depression: A Qualitative Synthesis of Patients' Experiences. Qualitative Health Research, 27(1), 100-113. https://doi.org/ $10.1177 / 1049732316681282$

Epstein, R. M., Duberstein, P. R., Feldman, M. D., Rochlen, A. B., Bell, R. A., Kravitz, R. L., .. Paterniti, D. A. (2010). "I didn't know what was wrong:" how people with undiagnosed depression recognize, name and explain their distress. Journal of General Internal Medicine, 25(9), 954-961. https://doi.org/10.1007/s11606-010-1367-0

Ferrari, A. J., Charlson, F. J., Norman, R. E., Patten, S. B., Freedman, G., Murray, C. J., . . Whiteford, H. A. 
(2013). Burden of depressive disorders by country, sex, age, and year: findings from the global burden of disease study 2010. PLOS Medicine, 10(11), e1001547. https://doi.org/10.1371/journal.pmed.1001547

Fiest, K. M., Currie, S. R., Williams, J. V., \& Wang, J. (2011). Chronic conditions and major depression in community-dwelling older adults. Journal of Affective Disorders, 131, 172-178. doi:10.1016/j.jad.2010.11.028

Gellis, Z. D. (2010). Depression Screening in Medically Ill Homecare Elderly. Best Practices in Mental Health, $6(6), 1-16$.

Graneheim, U. H., \& Lundman, B. (2004). Qualitative content analysis in nursing research: concepts, procedures and measures to achieve trustworthiness. Nurse Education Today, 24(2), 105-112. https://doi.org/ 10.1016/j.nedt.2003.10.001

Hegeman, J. M., Kok, R. M., van der Mast, R. C., \& Giltay, E. J. (2012). Phenomenology of depression in older compared with younger adults: meta-analysis. The British Journal of Psychiatry, 200, 275-281. https://doi.org/10.1192/bjp.bp.111.095950

Holm, A. L., Lyberg, A., Lassenius, E., Severinsson, E., \& Berggren, I. (2013). Older persons' lived experiences of depression and self-management. Issues in Mental Health Nursing, 34(10), 757-764. https://doi.org/10.3109/01612840.2013.809829

Holm, A. L., \& Severinsson, E. (2014). Surviving depressive ill-health: a qualitative systematic review of older persons' narratives. Nursing and Health Sciences, 16(1), 131-140. https://doi.org/10.1111/nhs.12071

Indu, P. S., Anilkumar, T. V., Pisharody, R., Russell, P. S. S., Raju, D., Sarma, P. S., . . Andrade, C. (2017). Prevalence of depression and past suicide attempt in primary care. Asian Journal of Psychiatry, 27, 48-52. https://doi.org/10.1016/j.ajp.2017.02.008

Jang, Y., Gum, A. M., \& Chiriboga, D. A. (2011). Knowledge of Depression Among Korean American Older Adults. Journal of Applied Gerontology, 30(5), 655-665. https://doi.org/10.1177/0733464810374468

Jorm, A. F. (2012). Mental health literacy: empowering the community to take action for better mental health. American Psychological Association, 67(3), 231-243. https://doi.org/10.1037/a0025957

Licht-Strunk, E., Beekman, A. T. F., de Haan, M., \& van Marwijk, H. W. J. (2009). The prognosis of undetected depression in older general practice patients. A one year follow-up study. Journal of Affective Disorders, 114, 310-315. https://doi.org/10.1016/j.jad.2008.06.006

Lopez, A. D., Mathers, C. D., Ezzati, M., Jamison, D. T., \& Murray, C. J. L. (2006). Global and regional burden of disease and risk factors, 2001: systematic analysis of population health data. The Lancet, 367(9524), 1747-1757. https://doi.org/10.1016/s0140-6736(06)68770-9

Ludman, E. J., Simon, G. E., Grothaus, L. C., Richards, J. E., Whiteside, U., \& Stewart, C. (2016). Organized Self-Management Support Services for Chronic Depressive Symptoms: A Randomized Controlled Trial. Psychiatric Services, 67(1), 29-36. https://doi.org/10.1176/appi.ps.201400295

Maiera, E. (2010). Old age depression and its treatment. Psychiatria Danubina, 22(suppl 1), 124-125.

Monteso, P., Ferre, C., Lleixa, M., Albacar, N., Aguilar, C., Sanchez, A., \& Lejeune, M. (2012). Depression in the elderly: study in a rural city in southern Catalonia. Journal of Psychiatric and Mental Health Nursing, 19(5), 426-429. https://doi.org/10.1111/j.1365-2850.2011.01798.x

Nilmanat, K., \& Street, A. F. (2014). Karmic quest: Thai family caregivers promoting a peaceful death for people with AIDS. Contemporary Nurse, 27(1), 94-103. https://doi.org/10.5172/conu.2007.27.1.94

Oakley LD, Kanter JW, Taylor JY, \& Duguid M. (2011). The self-stigma of depression for women. International Journal of Social Psychiatry, 58(5), 512-520. https://doi.org/10.1177/0020764011409820

Pagan-Rodriguez, R., \& Perez, S. (2012). Depression and self-reported disability among older people in Western Europe. Journal of Aging and Health, 24(7), 1131-1156. https://doi.org/10.1177/0898264312453070

Park, S., Hatim, A., Si, T. M., Jeon, H. J., Srisurapanont, M., Bautista, D., . . Hong, J. P. (2015). Stressful life events preceding the onset of depression in Asian patients with major depressive disorder. International Journal of Social Psychiatry, 61(8), 735-742. https://doi.org/10.1177/0020764015577842

Patton, M.Q. (2015). Qualitative research \& evaluation methods. (4th ed). Thousand oaks, CA: Sage.

Piek, E., Nolen, W. A., van der Meer, K., Joling, K. J., Kollen, B. J., Penninx, B. W., . . van Hout, H. P. (2012). 
Determinants of (non-)recognition of depression by general practitioners: results of the Netherlands Study of Depression and Anxiety. Journal of Affective Disorders, 138(3), 397-404. https://doi.org/ 0.1016/j.jad.2012.01.006

Polit, D. F., \& Beck, C. T. (2016). Nursing research: generating and assessing evidence for nursing practice (10th ed). Philadelphia, Wolters Kluwer.

Renaud, J., \& Bedard, E. (2013). Depression in the elderly with visual impairment and its association with quality of life. Clinical Interventions in Aging, 8, 931-943. https://doi.org/10.2147/CIA.S27717

Smyer, M. A., \& Qualls, S. H. (1999). Ageing and Mental Health. Oxford, Blackwell.

Stratmann, M., Konrad, C., Kugel, H., Krug, A., Schoning, S., Ohrmann, P., . . Dannlowski, U. (2014). Insular and hippocampal gray matter volume reductions in patients with major depressive disorder. PLOS One, 9(7), e102692. https://doi.org/10.1371/journal.pone.0102692

Su, L., Faluyi, Y. O., Hong, Y. T., Fryer, T. D., Mak, E., Gabel, S., . . O'Brien, J. T. (2016). Neuroinflammatory and morphological changes in late-life depression: the NIMROD study. The British Journal of Psychiatry, 209(6), 525-526. https://doi.org/10.1192/bjp.bp.116.190165

Thongtang, O., Vuthiganond, S., Sukhatunga, K., Pooviboonsuk, P., Ngamthipwatthana, T., Kooptiwoot, S., .....Phattharayuttawat, S. (2002). Prevalence and incidence of depression in Thai elderly. Journal of the Medical Association of Thailand, 85(5), 540-544.

Tiwari. S. C., Pandey, N.M., Singh, I. (2012). Mental health problems among inhabitants of old age homes: A preliminary study. Indian Journal of Psychiatry, 54(2), 144-148. https://doi.org/10.4103/0019-5545.99533

van Dijk, M. R., Utens, E. M., Dulfer, K., Al-Qezweny, M. N., van Geuns, R. J., Daemen, J., \& van Domburg, R. T. (2016). Depression and anxiety symptoms as predictors of mortality in PCI patients at 10 years of follow-up. European Journal of Preventive Cardiology, 23(5), 552-558. https://doi.org/10.1177/2047487315571889

Verhaak, P. F., Dekker, J. H., de Waal, M. W., van Marwijk, H. W., \& Comijs, H. C. (2014). Depression, disability and somatic diseases among elderly. Journal of Affective Disorder, 167, 187-191. https://doi.org/10.1016/j.jad.2014.05.057

Wangtongkum, S., Sucharitakul, P., Wongjareon, S., \& Maneechompoo, S. (2008). Prevalence of Depression among a Population Aged over45 years in Chiang Mai, Thailand. Journal of the Medical Association of Thailand, 91(12), 1812-1817.

World Health Organization. (2012). Depression is a common illness and people suffering from depression need support and treatment. Retrieved from: http://www.who.int/mediacentre/news/notes/2012/mental_health_day_20121009/en/

\section{Copyrights}

Copyright for this article is retained by the author(s), with first publication rights granted to the journal.

This is an open-access article distributed under the terms and conditions of the Creative Commons Attribution license (http://creativecommons.org/licenses/by/4.0/). 